\title{
GAUSS HÜZMESİNİN YÜKSEK FREKANSLARDA PLAZMA ORTAMLA ETKİLEŞİMİ
}

\author{
Selçuk Alparslan AVCI*, Erkan AFACAN \\ Gazi Üniversitesi, Mühendislik Fakültesi, Elektrik-Elektronik Mühendisliği Bölümü, 06570, Maltepe, Ankara \\ selcukavci@gazi.edu.tr, e.afacan@gazi.edu.tr
}

(Geliş/Received: 04.12.2014; Kabul/Accepted: 25.12.2014)

ÖZET

Sayısal yöntemler, elektromanyetik problemlerin çözümünde uzun yıllardan beri kullanılmaktadır. Bilgisayar teknolojisinin gelişmesi sayısal yöntemlerin yaygınlaşmasına yol açmıştır. Son yıllarda en çok kullanılan sayısal yöntemlerden bir tanesi zaman bölgesinde sonlu farklar yöntemidir (FDTD). Bu makalede, elektromanyetik dalgaların iki boyutlu plazma ortam içindeki yayılmaları zaman bölgesinde sonlu farklar yöntemi kullanılarak incelenmiştir. PML ve Mur tipi emici sınır koşulları (ABC) kullanılarak elektromanyetik dalgaların problem uzayının sınırlarında nasıl davrandığı araştırılmıştır. Yapılan simülasyonlarda, PML tipi emici sınır koşulunun Mur tipi emici sınır koşuluna göre daha iyi sonuç verdiği gösterilmiştir.

Anahtar Kelimeler: Zaman bölgesinde sonlu farklar yöntemi, yayılma, plazma ortam, gauss hüzmesi

\section{GAUSSIAN BEAM INTERACTION AT HIGH FREQUENCIES WITH PLASMA MEDIUM}

\begin{abstract}
Numerical methods have been used for the solution of electromagnetic problems for long years. The advancement of the computer technology has led the numerical methods to obtain a widespread usage. One of the most frequently used numerical methods in recent years is finite difference time domain method (FDTD). In this paper, the propagation of electromagnetic waves in a two dimensional plasma medium is investigated via finite difference time domain method. The behaviour of electromagnetic waves at the boundaries of the problem space has been studied by using PML and Mur type absorbing boundary conditions (ABC). In simulations, it is shown that PML type absorbing boundary condition gives better results than Mur type absorbing boundary condition.
\end{abstract}

Keywords: Finite difference time domain method, propagation, plasma medium, gaussian beam

\section{GIRISS (INTRODUCTION)}

Elektromanyetik problemlerin çözümlerinde en çok kullanılan sayısal yöntemlerden birisi zaman bölgesinde sonlu farklar yöntemidir (FDTD). Son zamanlarda bilgisayar teknolojisinin gelişmesi ile bu yöntem daha çok kullanılır hale gelmiştir. FDTD ilk olarak 1966 yilında K. S. Yee tarafindan tanıtılmıştır. Yee, Maxwell denklemleri için izotropik ortamlarda başlangıç sinır değer problemlerinin çözümünü doğrudan zaman bölgesinde bu sayısal yöntem ile gerçekleştirmiştir [1]. Daha sonra, Mur ve Berenger tarafından, Yee hücrelerinin kararlı sınır koşulları için emici elektromanyetik alan denklemleri zamanda sonlu farklar yöntemi ile düzenlenmiş̧ir. Bunun sonucunda iki ve üç boyutlu yapılarda elde edilen sayısal sonuçların emici sınır şartları açısından daha doğru olarak uygulanabileceği gösterilmiştir $[2,3]$. $\mathrm{Bu}$ makalede, serbest uzayda oluşturulan Gauss biçimli ve sinüzodial bir elektromanyetik dalganın plazma ortam ile karşılaştığında nasıl yayıldığı incelenmiştir.

\section{2. İKİ BOYUTLU FDTD DENKLEMLERİ (2D- FDTD EQUATIONS)}

FDTD Yöntemi, Maxwell denklemlerindeki kısmi türev operatörlerinin merkezi farklar yöntemine dayalı 
sonlu farklar karşılıkları ile değiştirilip, doğrudan zaman ve konum bölgelerinde sayısallaştırılmasına dayanır. Genel bir elektromanyetik dalga için iki boyutlu Maxwell denklemi,

$$
\begin{aligned}
& E_{z}{ }^{n+1}(i, j)=E_{z}{ }^{n}(i, j) \\
& +Z \frac{\Delta \tau}{\Delta x}\left[\begin{array}{l}
H_{y}{ }^{n+1 / 2}(i+1 / 2, j) \\
-H_{y}{ }^{n+1 / 2}(i-1 / 2, j)
\end{array}\right] \\
& -Z \frac{\Delta \tau}{\Delta y}\left[\begin{array}{l}
H_{x}{ }^{n+1 / 2}(i, j+1 / 2) \\
-H_{x}{ }^{n+1 / 2}(i, j-1 / 2)
\end{array}\right]
\end{aligned}
$$

şeklinde yazılabilir. Burada $Z$

$$
Z=\sqrt{\frac{\mu}{\varepsilon}}
$$

ile verilen plazma ortamın karakteristik empedansıdır.

\section{EMICI SINIR KOŞULLARI (ABSORBING BOUNDARY CONDITIONS)}

Emici sınır koşulları kullanılarak bölge sınırlarında elektromanyetik alan davranışının daha doğru bir şekilde modellenebileceği gösterilmiştir. Mur ve Berenger tarafindan geliştirilmiş olan iki tür emici sınır koşulu bulunmaktadır.

\subsection{Mur Tipi Emici Sınır Koşulu (Mur Type} Absorbing Boundary Condition)

FDTD yönteminde iterasyon sonucunda bir sonraki hücreye ait alan bileşenleri hesaplanmaktadır. Ancak bu bağıntıda sınırın dişarısında yer alan elektromanyetik alan bileşenlerine de ihtiyaç duyulduğundan sınır üzerindeki teğet manyetik ve elektrik alan bileşenlerinin değerleri bu şekilde elde edilemez. Bu yüzden açık bölge sınır koşullarının, sadece yüzeye teğet elektrik alan bileşenleri için elde edilmesi yeterlidir [4]. Tek yönlü dalga denklemi için oluşturulan emici sınır koşulu denklemi Mur tarafindan FDTD algoritmasina uygun hale getirilmiştir [2].

$$
\begin{aligned}
& E_{z}^{n+1}(0, j)=E_{z}^{n}(1, j) \\
& +\frac{c \Delta t-\Delta}{c \Delta t+\Delta}\left(E_{z}^{n+1}(1, j)-E_{z}^{n}(0, j)\right) .
\end{aligned}
$$

Burada $c$ 1şık hızıdır.

\subsection{PML Tipi Emici Sınır Koşulu (PML Type Absorbing Boundary Condition)}

Maxwell denklemleri için en esnek ve en etkili emici sınır şartlarından biri Berenger tarafindan geliştirilen mükemmel uyumlandırılmış tabaka (PML) yöntemidir. $\mathrm{Bu}$ yöntemde, bir A ortamında yayılan elektromanyetik dalganın farklı bir B ortamı ile karşılaşması durumunda, yansıma miktarı ortamların dielektrik sabitlerine ve manyetik geçirgenlik sabitlerine bağlı olarak değişir [3]. Elektriksel akı yoğunluğu $D_{z}$,

$$
\begin{array}{r}
D_{z}^{n+1 / 2}(i, j)=g_{i 3}(i) g_{j 3}(j) D_{z}^{n-1 / 2}(i, j) \\
+g_{i 2}(i) g_{j 2}(j)(0.5)\left[\begin{array}{l}
H_{y}{ }^{n}(i+1 / 2, j) \\
-H_{y}^{n}(i-1 / 2, j) \\
-H_{x}^{n}(i, j+1 / 2) \\
+H_{x}^{n}(i, j-1 / 2)
\end{array}\right]
\end{array}
$$

ile verilmiştir. Burada, $g_{i 2}, g_{i 3}$ ve $x_{n}(\mathrm{i})$ parametreleri,

$$
\begin{aligned}
& g_{i 2}(i)=\left(\frac{1}{1+x_{n}(i)}\right), \\
& g_{i 3}(i)=\left(\frac{1-x_{n}(i)}{1+x_{n}(i)}\right), \\
& g_{j 2}(j)=\left(\frac{1}{1+x_{n}(j)}\right),
\end{aligned}
$$

$$
g_{j 3}(j)=\left(\frac{1-x_{n}(j)}{1+x_{n}(j)}\right)
$$

$x_{n}(i)=0.33 x\left[\frac{i}{p m l_{-} b o y u}\right]^{3}$,

$\mathrm{i}=\mathrm{j}=1,2, . .$, pml_boyu

olarak verilmektedir. $x_{n}$, PML'in boyutlarına göre değişen bir katsayıdır.

\section{PLAZMA (PLASMA)}

Manyetize plazma ortamın dielektrik geçirgenlik sabiti [5];

$$
\varepsilon^{*}(\omega)=1+\frac{\omega_{P}{ }^{2}}{\omega\left(j v_{C}-\omega\right)}
$$

ile verilmektedir. Burada $\omega_{P}$

$$
\omega_{P}=2 \pi f_{P}
$$


şeklinde verilmekte olup, $v_{C}$ elektron çarpışma frekansını, $f_{P}$ plazma frekansını göstermektedir. (10) denklemi açılarak

$\varepsilon^{*}(\omega)=1+\frac{\omega_{P}^{2} / v_{C}}{j \omega}-\frac{\omega_{P}^{2} / v_{C}}{v_{C}+j \omega}$,

ifadesi elde edilir. (12) denkleminin Z- dönüşümü alındığında

$\varepsilon^{*}(\omega)=\frac{1}{\Delta t}+\frac{\omega_{P}^{2} / v_{C}}{1-z^{-1}}-\frac{\omega_{P}^{2} / v_{C}}{1-e^{-v_{C} \cdot \Delta t} z^{-1}}$,

elde edilir. (13) denkleminde elde edilen dielektrik sabiti (14) denkleminde yerine konulduğunda,

$D(z)=\varepsilon^{*}(z) E(z) \Delta t$,

$D(z)=E(z)+\frac{\omega_{P}^{2} \Delta t}{v_{C}}$.

$\left[\frac{\left(1-e^{-v_{C} \Delta t}\right) \cdot z^{-1}}{1-\left(1+e^{-v_{C} \cdot \Delta t}\right) z^{-1}+e^{-v_{C} \cdot \Delta t} z^{-2}}\right] \cdot E(z)$,

denklemi elde edilir.

\section{PLAZMA ORTAM SIMÜLASYONLARI (PLASMA MEDIUM SIMULATIONS)}

Sinüs ve Gauss darbelerinin çarpımıyla bir elektromanyetik dalga

$f(t)=e^{-0.5\left(\frac{t_{0}-T}{w}\right)^{2}} x \sin (2 \pi f \Delta t T)$,

şeklinde oluşturulmuştur. Burada $t_{0}$ darbenin başlangıç anındaki tepe noktasını, T periyodu, w darbenin genişliğini ve $\Delta t$ zaman adımını gösterir. PML tipi emici sınır koşulu için $i=80, j=80$ boyutunda bir hücre ve Mur tipi emici sınır koşulu için $i=100$, $\mathrm{j}=100$ boyutunda bir hücre kullanılmıştır.

PML tipi emici sınır koşulu için oluşturulan hücrede x-yönünde 40 ile 50 (Şekil 1), Mur tipi emici sınır koşulu için x-yönünde 50 ile 60 (Şekil 2) arasında plazma ortam, diğer yerlerde ise serbest uzay bölgesi oluşturulmuştur. Simülasyon sonuçları $\mathrm{C}++$ ve MATLAB programları ile elde edilmiştir.

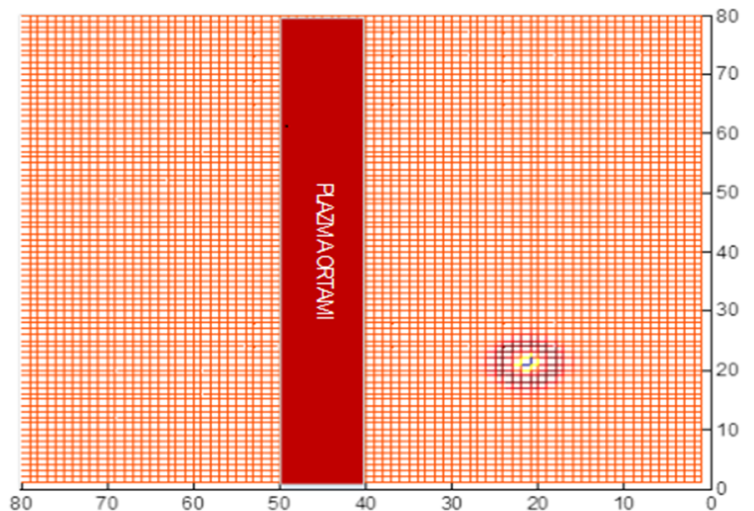

Şekil 1. PML tipi emici sınır koşulu için problem uzayı (Problem space for PML type ABC)

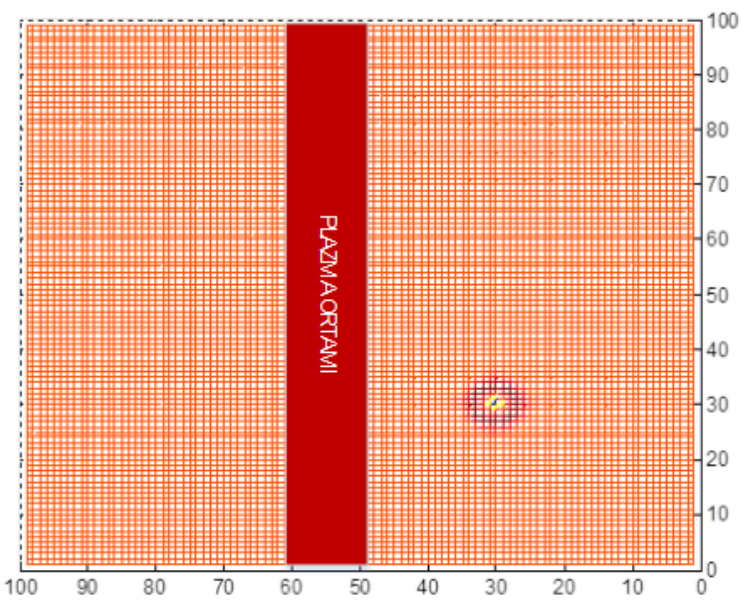

Şekil 2. Mur tipi emici sınır koşulu için problem uzayı (Problem space for Mur type ABC)

Şekil 3'de $\mathrm{n}=50$ zaman adımında serbest uzayda oluşan dalganın şekli gözlenmiştir (Mur tipi emici sınır koşulu kullanıldığında).

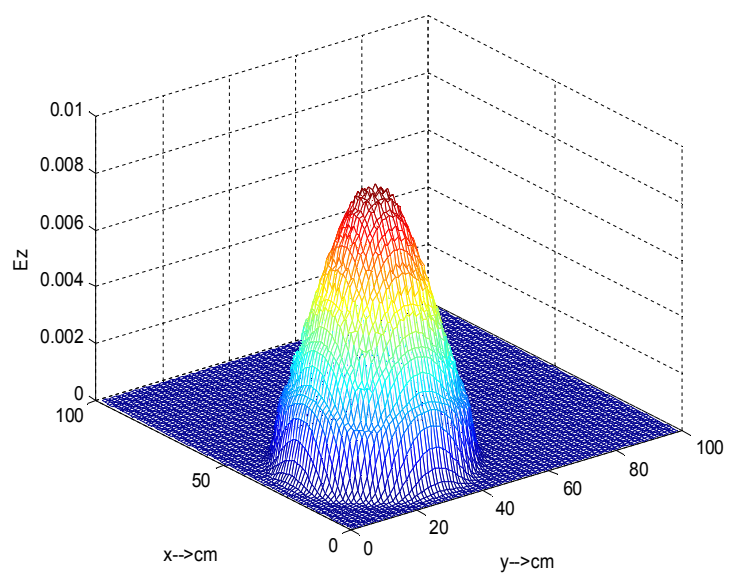

Şekil 3. Mur tipi emici sınır koşulu için $n=50$ zaman adımında elektromanyetik alan dağılımı (Electromagnetic field spread in $\mathrm{n}=50$ time step for Mur type $\mathrm{ABC}$ ) 
Şekil 4'de x-yönünde 50. ve 60. birim hücre arasında oluşturulan plazma ortamıyla karşılaşan dalganın plazma frekansı $500 \mathrm{THz}$ iken geri yansıdığı gözlenmiştir.

(Mur tipi emici sınır koşulu kullanıldığında).

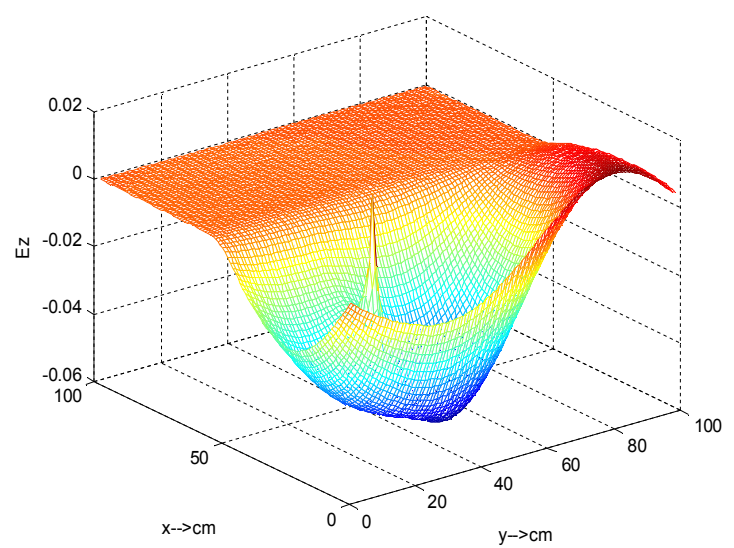

Şekil 4. Mur tipi emici sınır koşulu için n=300 zaman adımında elektromanyetik alan dağılımı (Electromagnetic field spread in $n=300$ time step for Mur type ABC)

Şekil 5'de n=50 zaman adımında serbest uzayda oluşan dalganın şekli gösterilmiştir

(Mur tipi emici sınır koşulu kullanıldığında).

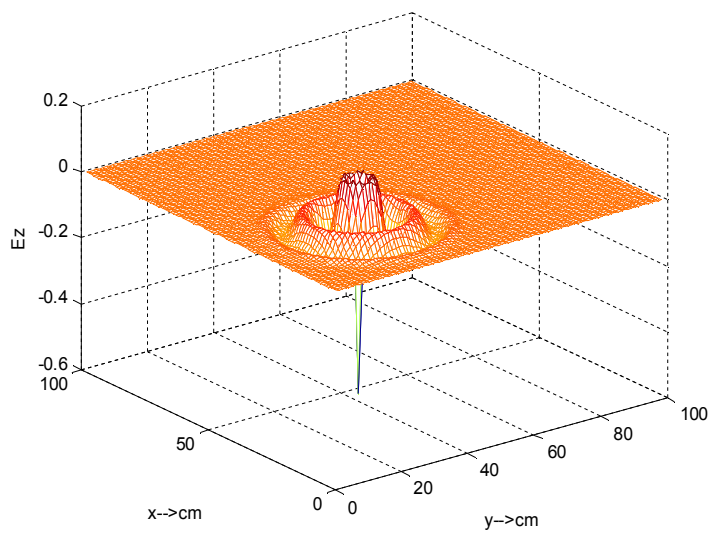

Şekil 5. Mur tipi emici sınır koşulu için $n=50$ zaman adımında elektromanyetik alan dağılımı (Electromagnetic field spread in $\mathrm{n}=50$ time step for Mur type $\mathrm{ABC}$ )

Şekil 6'da x-yönünde 50. ve 60. birim hücre arasında oluşturulan plazma ortamıyla karşılaşan dalga, plazma frekansı $4000 \mathrm{THz}$ iken plazma bölgesinden geçerek Mur tipi emici sınır koşulundan dolayı sönümlenmektedir

(Mur tipi emici sınır koşulu kullanıldığında).

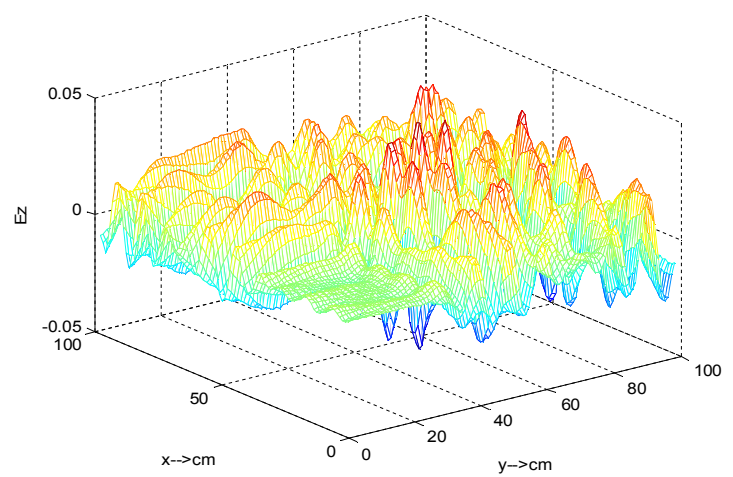

Şekil 6. Mur tipi emici sınır koşulu için n=300 zaman adımında elektromanyetik alan dağılımı (Electromagnetic field spread in $n=300$ time step for Mur type $A B C$ )

Şekil 7'de $\mathrm{n}=50$ zaman adımında dalganın serbest uzaydaki durumu gözlenmiştir (PML tipi emici sınır koşulu kullanıldığında).

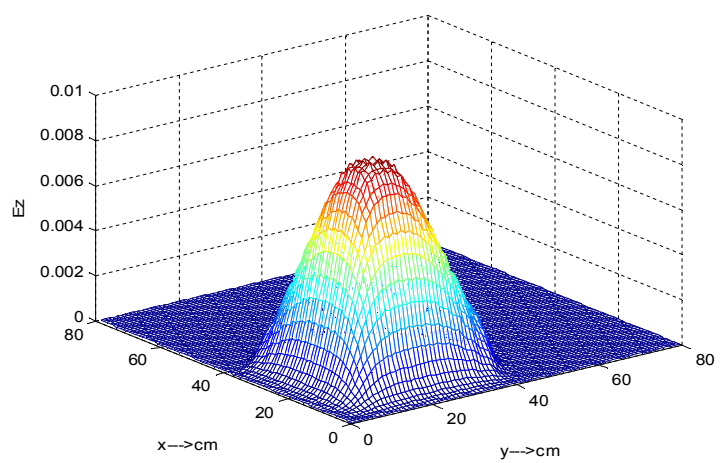

Şekil 7. PML tipi emici sınır koşulu için $n=50$ zaman adımında elektromanyetik alan dağılımı (Electromagnetic field spread in $\mathrm{n}=50$ time step for PML type ABC)

Şekil 8'de x-yönünde 40. ve 50. birim hücre arasında oluşturulan plazma ortamıyla karşılaşan dalganın plazma frekansı $500 \mathrm{THz}$ iken geri yansıdığ gözlenmiştir (PML tipi emici sınır koşulu kullanıldığında).

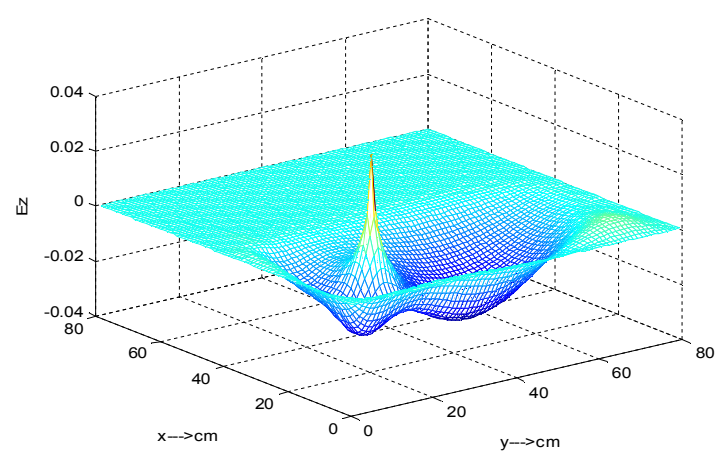

Şekil 8. PML tipi emici sınır koşulu için $n=300$ zaman adımında elektromanyetik alan dağılımı (Electromagnetic field spread in $\mathrm{n}=300$ time step for PML type $\mathrm{ABC})$ 
Şekil 9'da $\mathrm{n}=50$ zaman adımında dalganın serbest uzaydaki şekli gözlenmiştir (PML tipi emici sınır koşulu kullanıldığında).

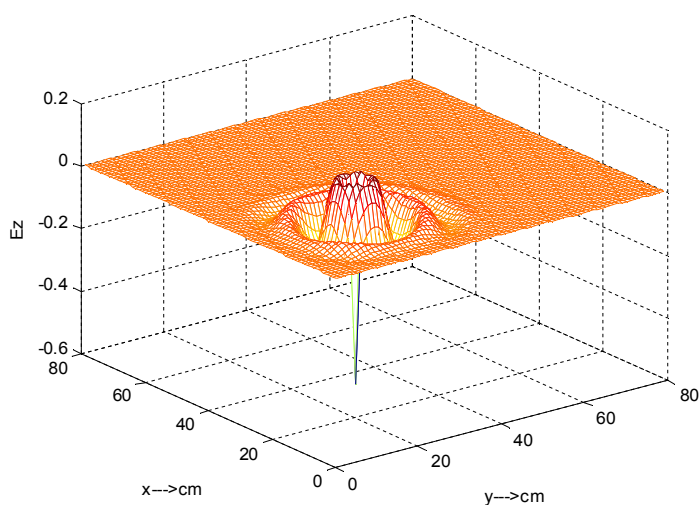

Şekil 9. PML tipi emici sınır koşulu için $n=50$ zaman adımında elektromanyetik alan dağılımı (Electromagnetic field spread in $n=50$ time step for PML type ABC)

Şekil 10 'da x-yönünde 40 . ve 50 . birim hücre arasında oluşturulan plazma ortamıyla karşılaşan dalga plazma frekans1 $4000 \mathrm{THz}$ iken plazma bölgesinden geçerek PML tipi emici sınır koşulundan dolayı sönümlenmektedir (PML tipi emici sınır koşulu kullanıldığında).

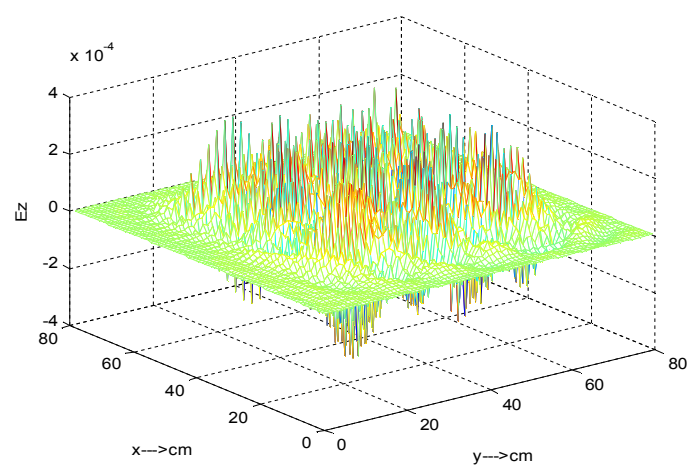

Şekil 10. PML tipi emici sınır koşulu için $n=300$ zaman adımında elektromanyetik alan dağılımı (Electromagnetic field spread in $\mathrm{n}=300$ time step for PML type $\mathrm{ABC})$
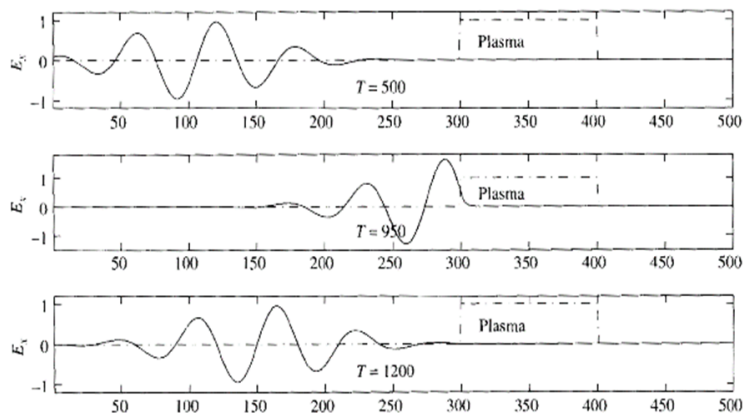

Şekil 11. Serbest uzayda yayılan ve plazma ortama çarpan elektromanyetik dalganın simülasyonu [5] (Simulation of an electromagnetic wave propagating in free space and striking a plasma medium)
Şekil 11'de 1D-FDTD için f=500 THz iken [5]'ten alınan sonuçlar ve Şekil 12 'de 1 D-FDTD için $\mathrm{f}=500$ $\mathrm{THz}$ iken bu çalışmada elde edilen sonuçlar görülmektedir. Her iki sonuçta da belli bir adımdan sonra plazma ortamiyla karşılaşan dalga plazma ortamdan geri yansımaktadır. [5] nolu referansta 2DFDTD için plazma ortam sonuçları olmadığından karşılaştırma yapılamamıştır.

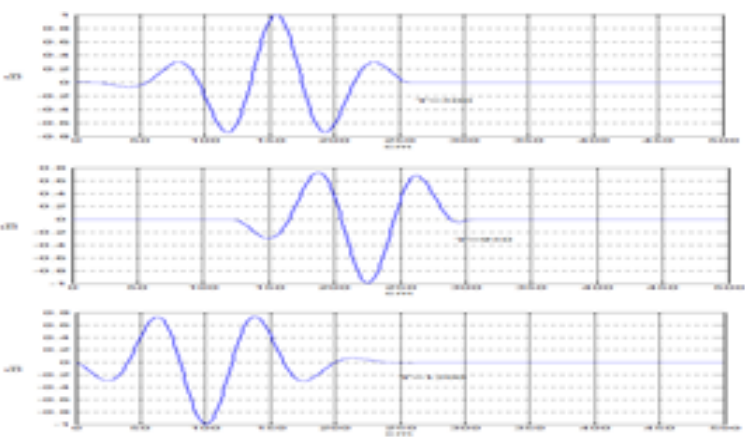

Sekil 12. Serbest uzayda yayılan ve plazma ortama çarpan elektromanyetik dalganın simülasyonu (Simulation of an electromagnetic wave propagating in free space and striking a plasma medium)
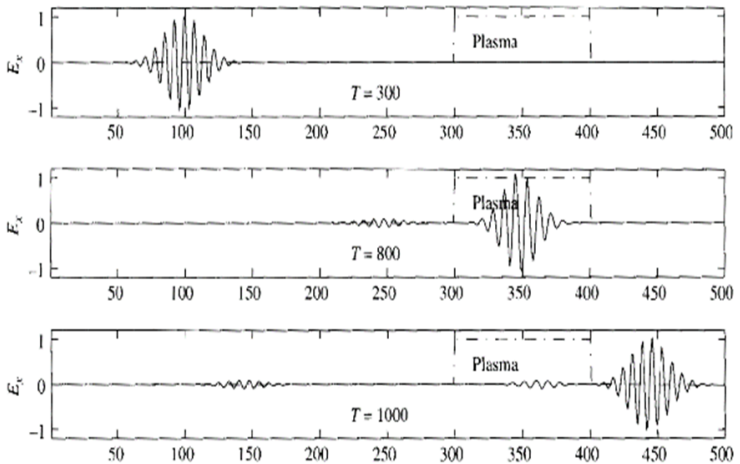

Şekil 13. Serbest uzayda yayılan ve plazma ortama çarpan elektromanyetik dalganın simülasyonu [5] (Simulation of an electromagnetic wave propagating in free space and striking a plasma medium)
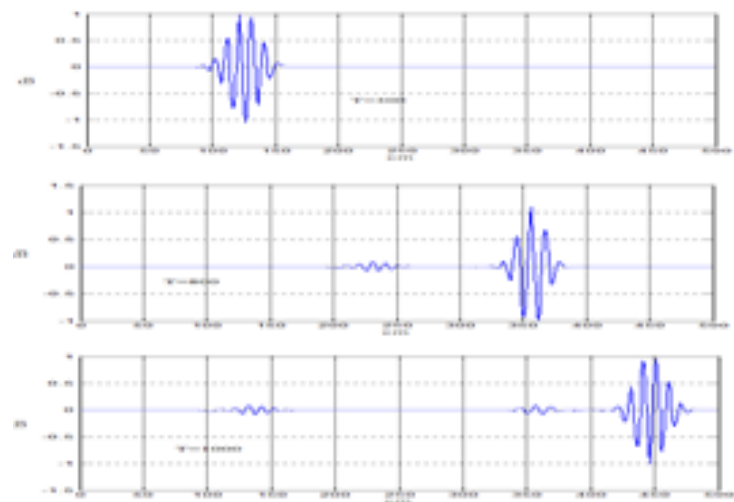

Şekil 14. Serbest uzayda yayılan ve plazma ortama çarpan elektromanyetik dalganın simülasyonu (Simulation of an electromagnetic wave propagating in free space and striking a plasma medium) 
Şekil 13'teki 1D-FDTD için f=4000 THz iken [5]'ten alınan sonuçlar ve Şekil 14'deki 1D-FDTD için $\mathrm{f}=4000 \mathrm{THz}$ iken bu çalışmada elde edilen sonuçlar yorumlandığında, her iki sonuçta da belli bir adımdan sonra plazma ortamla karşılaşan dalganın plazma ortamın içinden geçmiş olduğu görülmektedir.
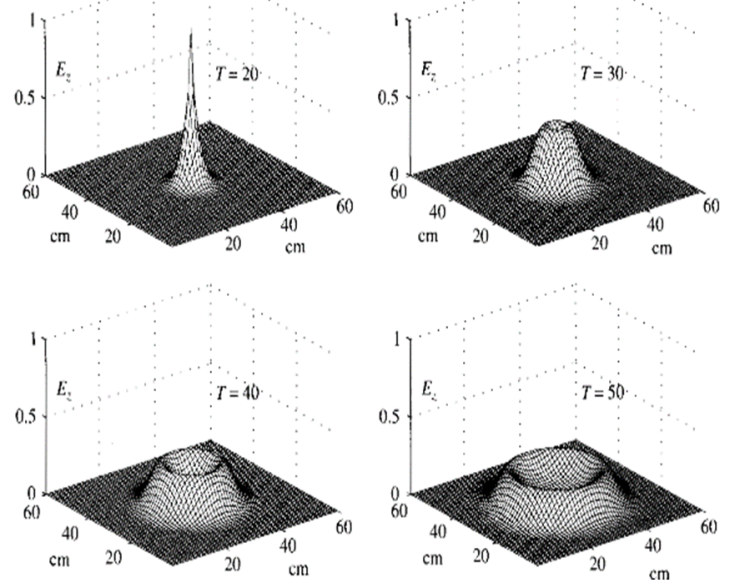

Şekil 15. 2D-FDTD için serbest uzayda oluşturulan Gauss darbesinin yayılımı [5] (Propagation of the created Gaussian pulse in free space for 2D-FDTD)
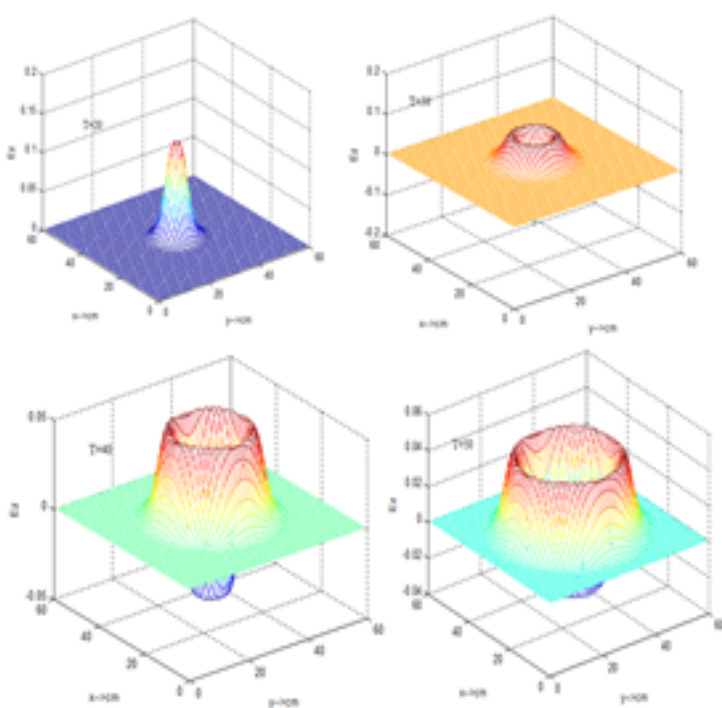

Şekil 16. 2D-FDTD için serbest uzayda oluşturulan Gauss darbesinin yayilimı (Propagation of the created Gaussian pulse in free space for 2D-FDTD)

Şekil 15'teki 2D-FDTD için serbest uzayda oluşturulan Gauss darbesinin yayılımının [5]'ten alınan sonuçları ile Şekil 16'da 2D-FDTD için bu çalışma kapsamında serbest uzayda oluşturulan Gauss darbesinin yayılımının sonuçları birbiri ile aynıdır.

Şekil 17'de 2D-FDTD için serbest uzayda oluşturulan Gauss darbesinin PML katmanına çarptığındaki davranışı [5] ile, Şekil 18'de 2D-FDTD için bu çalışma kapsamında serbest uzayda oluşturulan Gauss darbesinin PML katmanına çarptığındaki davranışı aynıdır.
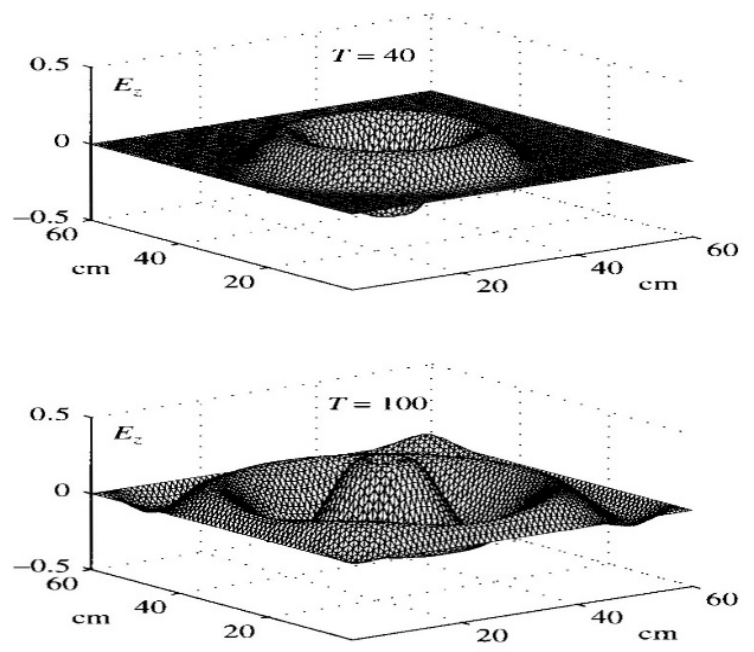

Şekil 17. 2D-FDTD için serbest uzayda oluşturulan Gauss darbesinin PML katmanına ulaştığındaki davranışı [5] (Behavior of the Gaussian pulse in free space when it reaches the PML layer for 2D-FDTD)

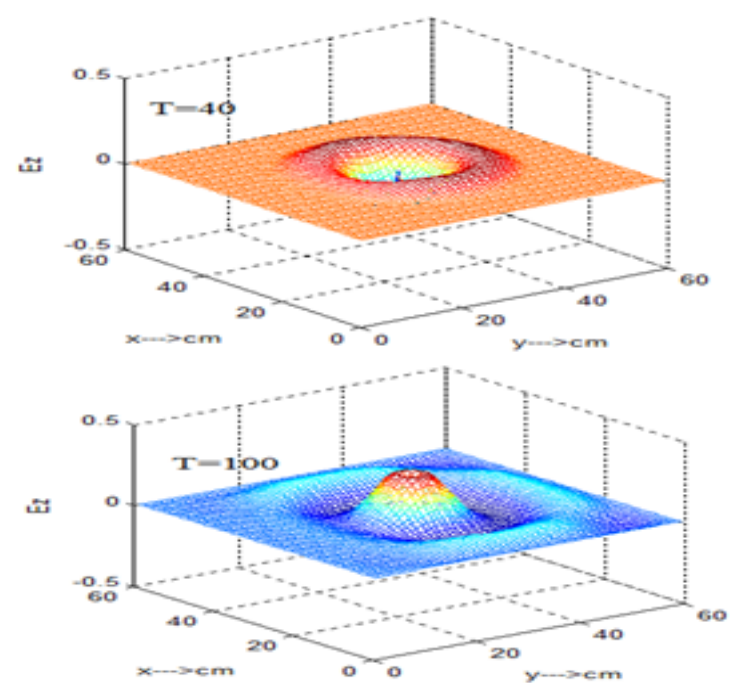

Şekil 18. 2D-FDTD için serbest uzayda oluşturulan Gauss darbesinin PML katmanına ulaştığındaki davranışı (Behavior of the Gaussian pulse in free space when it reaches the PML layer for 2D-FDTD)

\section{SONUÇ (CONCLUSION)}

$\mathrm{Bu}$ makalede, iki farklı emici sınır koşulu kullanılarak iki boyutlu zaman bölgesinde sonlu farklar yöntemi ile serbest uzayda oluşturulan elektromanyetik dalganın düşük frekanslarda plazma ortamından geri yansıdığı, yüksek frekanslarda ise plazma ortamından geçtiği ve ortam sınırlarında emici sınır koşullarından dolayı sönümlendiği gözlenmiştir.

İki emici sınır koşulundan PML tipi emici sınır koşulunun Mur tipi emici sınır koşuluna oranla daha iyi sonuç verdiği gösterilmiştir. Plazma ortamların elektromanyetik uyumluluk amaçlı olarak elektronik harp sistemlerinde kullanılması son zamanlarda yaygınlık kazanmaktadır. 


\section{KAYNAKLAR (REFERENCES)}

1. Yee, K. S., "Numerical Solutions of Initial Boundary Value Problems Involving Maxwell's Equations in Isotropic Media", IEEE Transactions Antennas Propagation, Cilt 14, No 3, 302-307, 1966.

2. Mur, G., "Absorbing Boundary Conditions for the Finite-Difference Approximation of the TimeDomain Electromagnetic Field Equations", IEEE Transactions Electromagnetic Compatibility, Cilt 23, No 4, 377-382, 1981.
3. Berenger, J. P., "A Perfectly Matched Layer for the Absorption of Electromagnetic Waves", Journal of Computational Physics, Cilt 114, No 2, 185-200, 1994.

4. Taflove, A. and Hagness, S. C., Computational Electrodynamics: The Finite Difference Time Domain, 3. Bask1, Artech House, Norwood, A.B.D., 2005.

5. Sullivan, D. M., Electromagnetic Simulation Using the FDTD Method, 2. Baskı, Wiley, New Jersey, A.B.D., 2013.. 
